\title{
Minimally Invasive Video-assisted Thyroidectomy vs Conventional Open Hemithyroidectomy in Asian Patients
}

\author{
${ }^{1}$ Anil D Rao, ${ }^{2}$ Reyaz M Singaporewalla, ${ }^{3}$ Arunesh Majumder
}

\begin{abstract}
Introduction: Although the technique of minimally invasive video assisted thyroidectomy (MIVAT) is well established in continental Europe, data on it's role in Asian patients is limited. We compared the results of MIVAT with conventional open hemithyroidectomy in Asian patients.
\end{abstract}

Materials and methods: Over a 1-year period, patients undergoing hemithyroidectomy for benign symptomatic goiters were selected. Inclusion criteria for MIVAT were benign colloid goiters, recurrent cysts or follicular lesions and neoplasms with lobe volume of less than $40 \mathrm{cc}$ or nodule diameter less than $35 \mathrm{~mm}$. Larger goiters underwent conventional open surgery. Patients with previous neck surgery and proven malignancy were excluded. Operative time, complications, postoperative pain score, incision length and cosmetic satisfaction at 6 months were recorded.

Results: Thirty-six patients (MIVAT-21, Conventional-15) were included. Both groups were comparable in terms of demographic profile and co-morbidities. The mean operating time for both groups showed no significant difference (MIVAT $=111.67$ $\pm 19.4 \mathrm{~min}$, Conventional $=112.40 \pm 25.06 \mathrm{~min} ; \mathrm{p}=0.925$ ). Minimally invasive video assisted thyroidectomy patients had significantly less pain in the immediate postoperative period (mean pain score 2.38 vs $4.8, p<0.001$ ). Mean incision length at end of surgery was significantly smaller in the MIVAT group (2.58 vs $6.3 \mathrm{~cm} ; p<0.001)$. Neck scar satisfaction at 6 months was excellent in $71.4 \%$ of MIVAT cases vs $26.6 \%$ of conventional hemithyroidectomy cases. There were no complications in any of the treatment groups.

Conclusion: In selected cases, MIVAT is as safe as conventional open surgery with distinct advantages of better postoperative pain control and cosmesis.

Keywords: Cosmesis, Minimally invasive, Pain, Thyroidectomy, Video-assisted.

How to cite this article: Rao AD, Singaporewalla RM, Majumder A. Minimally Invasive Video-assisted Thyroidectomy vs Conventional Open Hemithyroidectomy in Asian Patients. World J Endoc Surg 2016;8(3):189-192.

Source of support: Nil

Conflict of interest: None

\section{INTRODUCTION}

Minimally invasive video-assisted thyroidectomy (MIVAT) was first described in 1998 by Miccoli. ${ }^{1}$ Since then, this method has gained increasing popularity in continental

\footnotetext{
${ }^{1}$ Associate Consultant, ${ }^{2}$ Consultant, ${ }^{3}$ Registrar

${ }^{1-3}$ Department of Surgery, Khoo Teck Puat Hospital, Singapore

Corresponding Author: Anil D Rao, Associate Consultant Department of Surgery, Khoo Teck Puat Hospital, Singapore Phone: +6565558000, e-mail: dranilrao70@hotmail.com
}

Europe as a substitute for conventional open thyroidectomy in small-volume thyroid pathology. ${ }^{2-4}$ Studies in western literature have demonstrated that MIVAT is associated with reduced postoperative pain and improved cosmesis without significant increase in the operative time or complications. ${ }^{5}$ However, there is a paucity of data about the role of MIVAT in Asian patients. We therefore conducted a study comparing the outcome and results of MIVAT with conventional open thyroidectomy in our local population.

\section{MATERIALS AND METHODS}

This was a case-control study conducted in the endocrine surgical unit of a regional hospital. Data were prospectively collected from all patients undergoing hemithyroidectomy for symptomatic benign thyroid disorders either by MIVAT approach or by conventional open technique over a 1-year period (April 2011 to March 2012). All operations were performed by a single surgeon (SRM). The ultrasound ellipsoid algorithm of Brunn et al ${ }^{6}$ was used to calculate thyroid lobe and nodule volume. Inclusion criteria for MIVAT were patients with fine-needle aspiration cytology (FNAC) proven benign symptomatic goiter with a lobe volume of up to $40 \mathrm{cc}$ or dominant nodule diameter of less than $35 \mathrm{~mm}$. Patients with larger gland volumes underwent conventional open hemithyroidectomy. Patients with proven malignancy and history of previous neck surgery were excluded from the study. The MIVAT operation was carried out as per Miccoli's technique $^{1}$ [central cervical approach using a $1.5-2 \mathrm{~cm}$ incision (Fig. 1)]. All specimens in MIVAT operations were removed

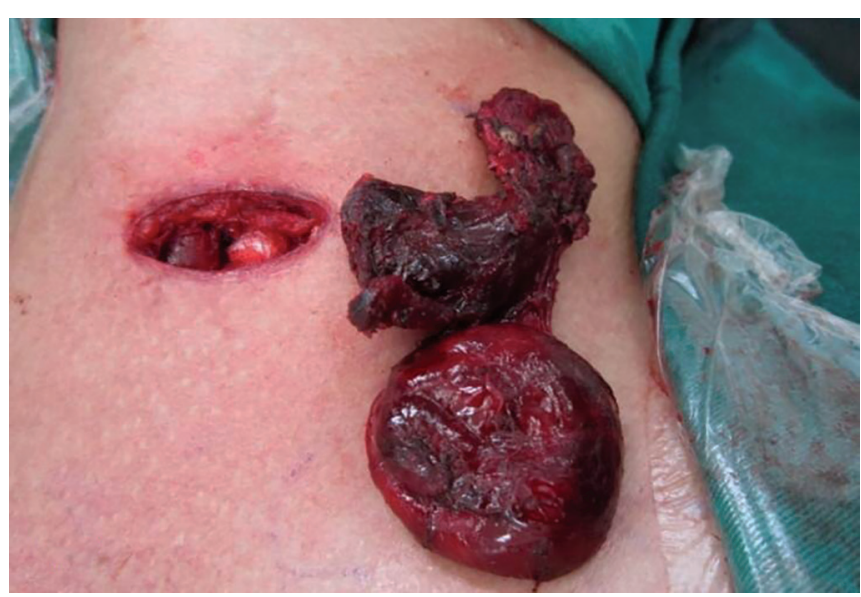

Fig. 1: Central cervical approach (Miccoli) 
intact without breaking the thyroid gland into small pieces. Conventional hemithyroidectomy was performed using a 4 to $6 \mathrm{~cm}$ skin crease neck incision. All the operations were performed using a sutureless technique with ultrasonic shears and clips for pedicle vascular division. Intraoperative nerve monitor was not used in any case. Incision length at the end of surgery, operative time, pain scores (immediate postoperative and the next morning), thyroid gland volume, and complications were recorded. Pain score was recorded using the visual analog scale where the patients are asked to record their pain with a numerical value ranging from 0 to 10 . Cosmetic satisfaction of both groups was evaluated at 4 to 6 months postoperatively, and patients were asked to grade the cosmetic outcomes as poor, satisfactory, and excellent.

\section{Statistical Analysis}

Ranked data were compared using Mann-Whitney $\mathrm{U}$ test. Continuous variables were analyzed using Student's t-test. Sex distribution in the two groups was compared using Fischer's exact test. The chi-square test was used to test cross-tabulated cosmetic satisfaction data. The $\mathrm{p}$-value of $<0.05$ was considered significant.

\section{RESULTS}

There were 21 patients in the MIVAT group and 15 patients in the open conventional thyroidectomy group over the 1-year study period. There was no statistical difference between the mean age and sex distribution in the two groups. The distribution of the thyroid pathologies in both groups is shown in Table 1. There was one conversion of MIVAT to conventional open technique due to technical difficulty in extracting the goiter intact. No major complication in terms of nerve injury or postoperative bleeding was noted in any patient. There was no significant difference in operating time in both the techniques (MIVAT $111.67 \pm 19.4$ min vs conventional $112.40 \pm 25.06 \mathrm{~min} ; \mathrm{p}=0.925)$.

The mean incision length at the end of operation for the MIVAT group was $2.58 \pm 0.16 \mathrm{~cm}$ vs $6.3 \pm 0.51 \mathrm{~cm}$ for the conventional group. This was statistically significant $(\mathrm{p}<0.005)$.

The mean pain scores in the immediate postoperative period recorded in the recovery room were $2.38 \pm 0.49$ for the MIVAT group vs $4.8 \pm 0.77$ for the conventional group ( $\mathrm{p}<0.005)$. On day 1 , the MIVAT group scores were $0.85 \pm 0.72$ vs $1.86 \pm 0.72$ for the conventional group $(p<0.001)$. The mean gland volumes in the MIVAT category were significantly smaller than the conventional group (Table 2).

Cosmetic satisfaction of the neck scar in the MIVAT group was rated as "excellent" by 15 patients $(71.4 \%$,
Table 1: Demographic profile and thyroid pathologies

\begin{tabular}{llll}
\hline & MIVAT & Conventional & $p$-value \\
\hline Age (in years) & $42.47 \pm 11.42$ & $42.10 \pm 19.49$ & 0.10 \\
M:F ratio & $5: 16$ & $3: 12$ & 0.73 \\
Thyroid pathology & Solitary nodule & 9 & 11 \\
& MNG & 8 & 4 \\
& Cyst & 4 & 0 \\
\hline
\end{tabular}

Table 2: Comparison of end points

\begin{tabular}{|c|c|c|c|}
\hline & MIVAT & Conventional & $p$-value \\
\hline Operative time (min) & $111.67 \pm 19.4$ & $112.40 \pm 25.06$ & 0.925 \\
\hline Gland volume (cc) & $24.86 \pm 13.66$ & $87.53 \pm 57.9$ & $<0.005$ \\
\hline Skin incision $(\mathrm{cm})$ & $2.58 \pm 0.16$ & $6.30 \pm 0.51$ & $<0.005$ \\
\hline $\begin{array}{l}\text { Pain score immediate } \\
\text { postop }\end{array}$ & $2.38 \pm 0.49$ & $4.8 \pm 0.77$ & $<0.005$ \\
\hline $\begin{array}{l}\text { Pain score postop } \\
\text { day } 1\end{array}$ & $0.85 \pm 0.72$ & $1.86 \pm 0.72$ & 0.001 \\
\hline $\begin{array}{l}\text { Cosmetic satisfaction } \\
\text { of neck scar } 6 \text { months }\end{array}$ & $\begin{array}{l}\text { Poor }-0 \\
\text { Satisfactory }-6 \\
\text { Excellent }-15\end{array}$ & $\begin{array}{l}\text { Poor }-4 \\
\text { Satisfactory }-7 \\
\text { Excellent }-7\end{array}$ & 0.008 \\
\hline
\end{tabular}

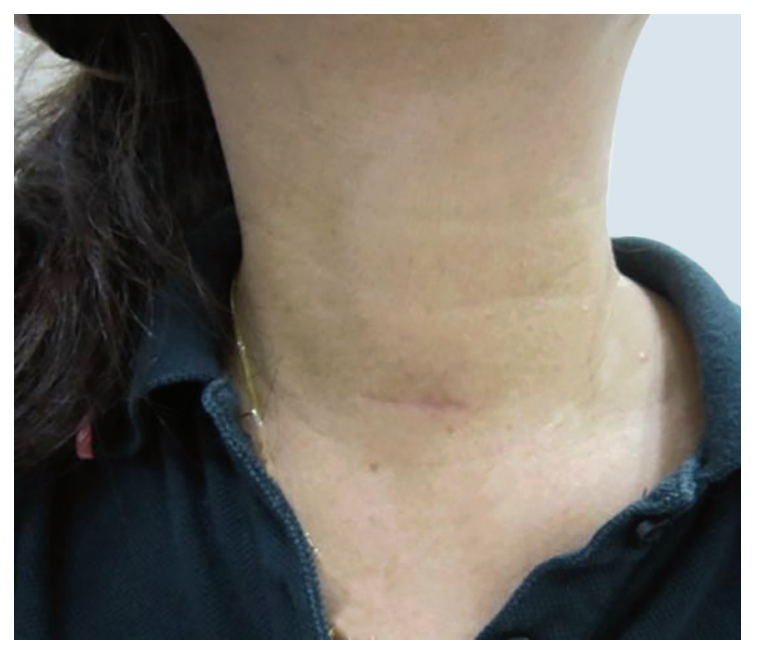

Fig. 2: Scar at 6 months

Fig. 2) and satisfactory by 6 . None of the patients rated the MIVAT scar as poor. In the conventional group, only 4 patients rated their neck scars as excellent (26.6\%), while 7 patients rated their scars as satisfactory and 4 as poor.

The mean follow-up period was 7.2 months (4-12 months).

\section{DISCUSSION}

One of the biggest apprehensions for Asian patients undergoing thyroid surgery is the appearance of the neck scar. In young patients needing a thyroidectomy, the cosmetic impact of a large neck scar can be significant and can impair the quality of life. ${ }^{7}$ In our population, the length of the neck scar does have a significant impact on the patients' quality of life. Therefore, the option of MIVAT allows in certain selected cases, to perform a 
thyroid surgery with excellent results using a mini neck incision. The MIVAT technique is different from other purely endoscopic thyroidectomy techniques via the axilla or breast because it is truly a minimally invasive approach compared to other remote maximally invasive approaches offered by the axillary and breast techniques which require more dissection, need for drains and are associated with longer hospitalization. Using the clear and magnified high definition vision and light from the endoscope through a small 1.5 to $2.5 \mathrm{~cm}$ central skin crease neck incision, it is possible to perform a thyroidectomy safely with excellent visualization of important structures identical to conventional thyroidectomy. One of the main advantages of the MIVAT is that it allows safe division of the superior vascular pedicle under excellent magnified visualization followed by delivery of the gland outside the incision to allow subsequent safe dissection of the nerve and parathyroid glands just like open surgery. In the western population, studies have been performed comparing MIVAT with conventional thyroidectomy in a randomized trial. The first randomized controlled trial comparing MIVAT with conventional open hemithyroidectomy was conducted by Miccoli et al. ${ }^{5}$ This was followed up with another prospective randomized trial by the same group focusing on treating thyroid malignancy, specifically low-risk papillary cancer. Both these randomized studies established the feasibility and efficacy of MIVAT. ${ }^{8}$ One drawback associated with MIVAT in the first study was a longer operative time. ${ }^{9}$ However, in our study, the operative duration was comparable to open surgery. A study by Terris et $\mathrm{al}^{10}$ in 2005 compared conventional open thyroidectomy to minimally invasive thyroidectomy using a significantly smaller incision with transection of the strap muscles (Sofferman technique). ${ }^{11}$ However, in our opinion the key limiting factor in extracting the goiter in MIVAT is the skin incision length, and division of the strap muscles may not necessarily allow the gland to be extracted intact for histological assessment. If the specimen were to be extracted piecemeal, then even larger gland volumes can be selected for this approach based on institutional policy regarding pathological specimens. In the recent series of Liu et $\mathrm{al}_{1}{ }^{12}$ complications were shown to be comparable between the two groups with the MIVAT technique having a longer operating time. Minimally invasive video-assisted thyroidectomy, however, offered distinct advantages in selected cases, of better cosmesis and lesser pain. A recent meta-analysis by Pisanu et $\mathrm{a}^{13}$ comparing MIVAT and conventional thyroidectomy showed a shorter postoperative stay and improved cosmesis associated with MIVAT.

It is intuitive that smaller incisions give lesser pain as has been the experience with all laparoscopic proce- dures and minimally invasive surgery. We believe that besides the small skin scar of MIVAT, another reason for the significantly lower postoperative pain scores is that the degree and force of muscle retraction is much less than conventional open surgery. Smaller incisions are not expected to make the surgery difficult in any way with more retraction as part of the procedure. On the contrary, the procedure is akin to any keyhole surgery with more emphasis on focused precise moves, steps and dissection aided by high definition camera vision, making excessive muscle retraction unnecessary. A key element in the successful completion of the MIVAT procedure is to respect tissues planes and avoid bleeding during dissection as identification of key structures, such as parathyroid glands and the nerves becomes difficult once bleeding starts.

A slightly higher incidence of thermal skin injury has been documented in the study of Vaysberg et $\mathrm{al}^{14}$ who demonstrated equivalent results between the two in terms of hypocalcemia, hematoma, and vocal cord paresis. The skin bruising and thermal skin injury can be minimized by careful use of diathermy and nonmetal retractors that do not allow heat conduction.

The main limitation of the MIVAT technique is goiter size and traditionally a thyroid lobe volume of $35 \mathrm{cc}$ or a nodule diameter of $35 \mathrm{~mm}$ is quoted as the upper limit for a successful delivery of the lobe out of the small skin incision. In our institution, it is standard policy to remove specimens intact for pathology. This was the reason for one conversion in the MIVAT group due to technical difficulty in removing the thyroid lobe intact. An additional drawback of the MIVAT procedure is the requirement of two assistants, one of whom has to be a trained camera holder. Some researchers have published results with the use of a camera holding device to overcome the drawback of undesired camera movements. ${ }^{15}$ According to the work published by Ruggieri et al, ${ }^{16}$ it is possible to extend the role of MIVAT for glands up to a volume of $50 \mathrm{cc}$ by varying incision size from 20 to $35 \mathrm{~mm}$. Our study clearly demonstrates a significantly lower pain score associated with MIVAT and a significantly smaller incision. It is noteworthy that there is no significant difference in the operative time or complications between the two groups in this study. This proves the efficacy and safety of MIVAT in comparison to conventional open hemithyroidectomy. The authors believe a 30 case-learning curve for an advanced laparoscopic surgeon should be sufficient to learn the MIVAT procedure. The learning curve, technical evolution of surgical instrumentation, and availability of a dedicated surgical team can play a role in reducing the operating times such that MIVAT can eventually rival conventional surgery in selected 
symptomatic small-volume thyroid disease. Currently, there is increasing trend toward performing MIVAT for malignant pathologies but limiting it to low-risk cancers. Del Rio et $\mathrm{al}^{17}$ have shown MIVAT to have the same level of radicality at the thyroid bed level in papillary cancer. More recent reports have also shown that central and lateral compartment clearance can also be performed with videoscopic procedures. ${ }^{18}$

In conclusion, as long as strict selection criteria are followed, MIVAT is a feasible and safe option for symptomatic small-volume thyroid pathologies needing surgery. It avoids the need for a larger neck scar with distinct advantages in terms of cosmesis and postoperative pain.

\section{REFERENCES}

1. Miccoli P, Berti P, Conte M, Bendinelli C, Marcocci C. Minimally invasive surgery for thyroid small nodules: preliminary report. J. Endocrinol Invest 1999 Dec;22(11):849-851.

2. Zhang P, Zhang HW, Han XD, Di JZ, Zheng Q. Meta-analysis of comparison between minimally invasive video-assisted thyroidectomy and conventional thyroidectomy. Eur Rev Med Pharmacol Sci 2015 Apr;19(8):1381-1387.

3. Piniek A, Schuhmann R, Coerper S. Minimally invasive video-assisted thyroidectomy: establishment in a thyroid center. Chirurg 2014 Mar;85(3):246-252.

4. Del Rio P, Bezer L, Palladino S, Arcuri MF, Iotti E, Sianesi M. Operative time and postoperative pain following minimally invasive video-assisted parathyroidectomy. G Chir 2010 Apr;31(4):155-158.

5. Miccoli P, Berti P, Raffaelli M, Materazzi G, Baldacci S, Rossi G. Comparison between minimally invasive video-assisted thyroidectomy and conventional thyroidectomy: a prospective randomized study. Surgery 2001 Dec;130(6):1039-1043.

6. Brunn J, Block U, Ruf G, Bos I, Kunze WP, Scriba PC. Volumetric analysis of thyroid lobes by real-time ultrasound. Dtsch Med Wochenschr 1981 Oct;106(41):1338-1340.

7. Arora A, Swords C, Garas G, Chaidas K, Prichard A, Budge J, Davies DC, Tolley N. The perception of scar cosmesis follow- ing thyroid and parathyroid surgery: a prospective cohort study. Int J Surg 2016 Jan;25:38-43.

8. Minuto MN, Berti P, Miccoli M, Ugolini C, Matteucci V, Moretti M, Basolo F, Miccoli P. Minimally invasive videoassisted thyroidectomy: an analysis of results and a revision of indications. Surg Endosc 2012 Mar;26(3):818-822.

9. Capponi MG, Bellotti C, Lotti M, Ansaloni L. Minimally invasive video-assisted thyroidectomy: ascending the learning curve. J Minim Access Surg 2015 Apr-Jun;11(2):119-122.

10. Terris DJ, Bonnett A, Gourin CG, Chin E. Minimally invasive thyroidectomy using the Sofferman technique. Laryngoscope 2005 Jun; 115(6):1104-1108.

11. Pfuetzenreiter EG Jr, Dedivitis RA, Guimaraes AV. Minimally invasive thyroidectomy using the Sofferman technique. Laryngoscope 2006 Sep;116(9):1719.

12. Liu J, Song T, Xu M. Minimally invasive video-assisted versus conventional open thyroidectomy: a systematic review of available data. Surg Today 2012 Sep;42(9):848-856.

13. Pisanu A, Podda M, Reccia I, Porceddu G, Uccheddu A. Systematic review with meta-analysis of prospective randomized trials comparing minimally invasive video-assisted thyroidectomy (MIVAT) and conventional thyroidectomy. Langenbecks Arch Surg 2013 Dec;398(8):1057-1068.

14. Vaysberg M, Steward DL. Minimally invasive video assisted thyroidectomy. Laryngoscope 2008 May;118(5):786-789.

15. Rulli F, Galata G, Pompeo E, Farinon AM. A camera handler for Miccoli's minimally invasive video-assisted thyroidectomy and parathyroidectomy procedures. Surg Endosc 2007 Jun;21(6):1017-1019.

16. Ruggieri M, Straniero A, Genderini M, D'Armiento M, Fumarola A, Trimboli P, Gargiulo P. The eligibility of MIVA approach in thyroid surgery. Langenbecks Arch Surg 2007 Jul;392(4):413-416.

17. Del Rio P, Maestroni U, Sianesi M, Viani L, Vicente D, Stojadinovic A, Avital I. Minimally invasive video-assisted thyroidectomy for papillary thyroid cancer: a prospective 5-year follow-up study. Tumori 2015 Mar-Apr;101(2):144-1447.

18. Zhang Z, Xu Z, Li Z, An C, Liu J, Zhu Y, Ni S, Tang P, Sayan A, Ilankovan V. Minimally-invasive endoscopicallyassisted neck dissection for lateral cervical metastases of thyroid papillary carcinoma. Br J Oral Maxillofac Surg 2014 Nov;52(9):793-797. 